Vol. 11 (3): 395-402 (2021)

\title{
NOSOCOMIAL INFECTIONS IN PEDIATRIC INTENSIVE THERAPY
}

\author{
Rudina Pirushi $^{1 *}$, Denisa Bego ${ }^{1}$, Zamira Imeraj ${ }^{1}$, Valbona Bilali ${ }^{1}$, \\ Valbona Alliu', Ferit Zavalani ${ }^{2}$ \\ ${ }^{1 *}$ University of Medicine, Faculty of Medical Technical Sciences, Tirana, Albania; \\ ${ }^{2}$ University of Medicine, Service of Infectious Diseases, University Hospital Center, Tirana, Albania; \\ *Corresponding Author Rudina Pirushi, e-mail: pirushirudi@yahoo.com;
}

Received March 2021; Accepted April 2021; Published May 2021;

DOI: https://doi.org/10.31407/ijees11.306

\begin{abstract}
Purpose. This is a prospective study with the purpose of presenting strategies to reduce the risk of Nosocomial infections in pediatric intensive care at Universitary Hospital Center "Mother Teresa", Tirana, during the period October 2019 - March 2020. Method. The study included 280 patients (0-14 years old) hospitalized in Pediatric Intensive Care, and were monitored every day from the moment of admission to the exit. Results. During the period October 2019 - March 2020, 10 (3\%) patients out of 280 (97\%) children admitted to the Pediatric Intensive Care, resulted with nosocomial respiratory tract infection. Pseudomonas aeruginosa in $40 \%$ of cases is the most common cause of nosocomial infections in Intensive Care Pediatrics. The average hospital stay for patients without nosocomial respiratory tract infection was 3.6 days, while those with nosocomial respiratory tract infection was 18.8 days $(\mathrm{p}<0.01)$, regarding to nosocomial urinary tract infections, $13(4.6 \%)$ patients out of $280(95.4 \%)$ patients resulted positive. Escherichia Coli in $38 \%$ of cases is the most common cause of nosocomial infections in Intensive Care Pediatrics. Comparison of average of urinary catheters duration in patients with urinary tract infection 3.1 days and them without urinary tract infection 1.5 days $(\mathrm{p}<0.01)$. Conclusions. Medical and nursing staff play an important role in the dynamic tracking of hospitalized children in intensive pediatric care. Hand washing with bactericidal solutions, use of aseptic techniques during patient manipulation, continuous bacteriological control of the environment, etc., is the strategy for prevention of infections in pediatric intensive care units.
\end{abstract}

Keywords: Nosocomial, Respiratory, Urinary, Intensive Therapy. 